\title{
Serum Protein Electrophoresis: An Underused but Very Useful Test
}

\author{
Stephan R. Vavricka ${ }^{a}$ b Emanuel Burri ${ }^{a} \quad$ Christoph Beglinger ${ }^{a} \quad$ Lukas Degen $^{a}$ \\ Michael Manz ${ }^{\mathrm{a}}$ \\ ${ }^{a}$ Division of Gastroenterology and Hepatology, University Hospital, Basel, and ${ }^{b}$ Division of Gastroenterology and \\ Hepatology, University Hospital, Zürich, Switzerland
}

\section{Key Words}

Serum protein electrophoresis $\cdot \alpha_{1}$-Antitrypsin deficiency $\cdot$ Diagnostic test $\cdot$ Hypogammaglobulinemia $\cdot$ Liver disease

\begin{abstract}
Serum protein electrophoresis is used in clinical practice to identify patients with multiple myeloma and other serum protein disorders. It is an inexpensive and easy-to-perform screening procedure. Electrophoresis separates serum proteins based on their physical properties and identifies morphologic patterns in response to acute and chronic inflammation, various malignancies, liver or renal failure, and hereditary protein disorders. For gastroenterologists, the use of serum protein electrophoresis may be helpful in the diagnosis of both common diseases with unusual presentations and rare disorders with typical presentations. Therefore, it represents an ideal screening tool.
\end{abstract}

Copyright $\odot 2009$ S. Karger AG, Basel

\section{Introduction}

Serum protein electrophoresis (SPE) is a laboratory technique that examines specific serum proteins called globulins. Serum (fluid portion of the blood without clotting factors) is placed on special paper treated with agarose gel and exposed to an electric current that separates serum proteins into five fractions by size and electrical charge [1]. The proteins are then stained and their density is measured to provide graphical data that is easier to interpret. The main fractions are albumin and $\alpha_{1^{-}}, \alpha_{2^{-}}$, $\beta$-, and $\gamma$-globulins (fig. 1a) and comprise around 13 different proteins. Further separation of different subsets of proteins is done by immunofluorescence and immunofixation. In clinical practice, SPE is commonly used to identify patients with multiple myeloma and other disorders of serum protein and is often used as a screening test in the initial evaluation of a patient. Unfortunately, gastroenterologists tend to underuse this technique, probably due to lack of knowledge and inexperience in interpreting the results. This is a pity since the test is very inexpensive if compared to other laboratory parameters. The aims of this article are therefore to review the literature on SPE and to present a simple and comprehensive guide on its use and interpretation in the clinical setting.

\section{Components of Serum Protein Electrophoresis}

Two major types of proteins can be identified with SPE: albumin and globulins. To interpret the results, the main focus is set on the relative and absolute quantity of the various subsets of these proteins. The physiologic distribution is presented in table 1 and characteristic patterns for various disorders are presented in table 2 [1-3].

\section{KARGER \\ Fax +41613061234 E-Mail karger@karger.ch} www.karger.com
Stephan R. Vavricka, MD

Division of Gastroenterology and Hepatology, University Hospital

Rämistrasse 100, CH-8091 Zürich (Switzerland)

Tel. +41 44255 2124, Fax +41 442554503

E-Mail stephan.vavricka@usz.ch 

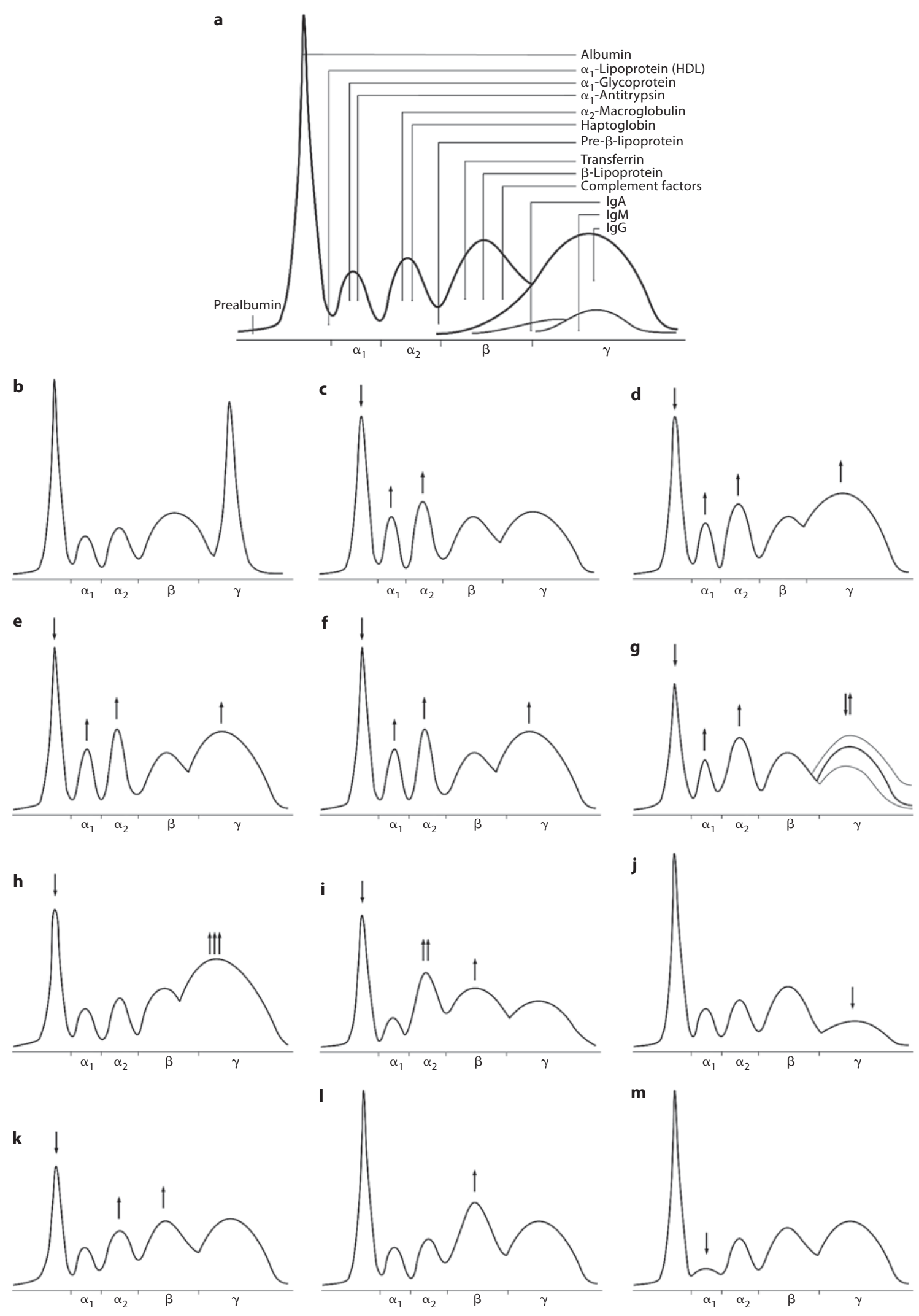


\section{Albumin}

Albumin represents the major component of serum proteins and may be decreased due to anabolic failure or catabolic metabolism. It is produced by the liver under normal physiologic conditions. On the graphical output of SPE it forms the largest peak and lies closest to the positive electrode (anode) on the left side of the panel. A fall in serum levels of larger than $30 \%$ is necessary to be detected with electrophoresis. Malnutrition, liver failure, renal loss (e.g. nephrotic syndrome), hormone therapy, burns or pregnancy may account for a low albumin level. Albumin is usually represented with a large single band, but in rare disorders such as bisalbuminemia (heterozygote form), albumin may produce two equally staining bands. Occasionally, a single wide band or two bands of unequal intensity may also be seen, but both of these variants are not associated with any disease. The formation of these variants results from increased mobility of albumin due to binding of bilirubin, nonesterified fatty acids, penicillin or acetylsalicylic acid to albumin. In acute pancreatitis, tryptic digestion of albumin may result in the same morphologic pattern. Absence of albumin is very rare. This condition is called analbuminemia. Increased levels of serum albumin can be found in patients with dehydration.

Table 1. Electrophoretic distribution of serum proteins

\begin{tabular}{lcc}
\hline & $\begin{array}{l}\text { Distribution } \\
\%\end{array}$ & $\begin{array}{l}\text { Absolute } \\
\text { amount, g/l }\end{array}$ \\
\hline Albumin & 55 & 40 \\
$\alpha_{1}$-Globulin & 5 & 4 \\
$\alpha_{2}$-Globulin & 10 & 7 \\
$\beta$-Globulin & 12 & 9 \\
$\gamma$-Globulin & 18 & 13 \\
\hline Total & 100 & 73 \\
\hline
\end{tabular}

Fig. 1. a Normal pattern of SPE. Proteins are compromised in five fractions (albumin and $\alpha_{1^{-}}, \alpha_{2^{-}}, \beta$-, and $\gamma$-globulin; b monoclonal gammopathy; c acute inflammation response, early phase; $\mathbf{d}$ acute inflammation response, late phase; e chronic inflammation; $\mathbf{f}$ chronic active inflammation; $\mathbf{g}$ malignant tumor; $\mathbf{h}$ liver cirrhosis; i nephrotic syndrome; $\mathbf{j}$ antibody deficiency; k pregnancy; $\mathbf{I}$ iron-deficiency anemia, and $\mathbf{m} \alpha_{1}$-antitrypsin deficiency.

\section{The Globulins}

The globulins comprise a much smaller fraction of the total serum protein content. The four components of globulins are labeled $\alpha_{1}, \alpha_{2}, \beta$ and $\gamma$. The peaks for these components lie towards the negative electrode (cathode) on the right side of the graphical output, with the $\gamma$-peak being closest to the cathode.

\section{Albumin- $\alpha_{1}$-Interzone}

Even staining in this zone is due to $\alpha_{1}$-lipoprotein (high-density lipoprotein). A decrease can be found in severe inflammation, acute hepatitis and liver cirrhosis or in nephrotic syndrome when proteins are lost through leaky glomeruli. An increase of the $\alpha_{1}$-interzone can be found in severe alcoholism and under physiological circumstances in women during pregnancy or in young people during puberty. High levels of $\alpha$-fetoprotein (AFP) from hepatocellular carcinoma may result in a sharp band in the $\alpha_{1}$-interzone.

\section{$\alpha_{1}$-Zone}

The $\alpha_{1}$-protein fraction is comprised of AFP, $\alpha_{1}$-glycoprotein, thyroid-binding globulin, and transcortin. A decreased band is seen in deficiency states such as AFP deficiency, nephrotic syndrome and liver failure from cirrhosis. Bence Jones protein from multiple myeloma may bind to and retard the $\alpha_{1}$-band and thus also lead to a decreased $\alpha_{1}$-zone, whereas in other malignancies or during inflammatory responses an increase of the $\alpha_{1}$-protein band may result from acute-phase reactants.

\section{$\alpha_{1}-\alpha_{2}$-Interzone}

Two faint bands may be seen representing $\alpha_{1}$-antichymotrypsin and vitamin $\mathrm{D}$ binding protein. These bands fuse and intensify in early inflammation due to an increase in $\alpha_{1}$-antichymotrypsin, an acute-phase protein.

\section{$\alpha_{2}$-Zone}

Ceruloplasmin, $\alpha_{2}$-macroglobulin, and haptoglobin contribute to the $\alpha_{2}$-protein band. The $\alpha_{2}$-zone is typically decreased in hemolytic anemia when haptoglobin binds with free hemoglobin from red blood cells and these complexes are rapidly removed by phagocytes. Haptoglobin may also be elevated, especially during inflammation as part of the acute-phase response. Children and elderly people show higher levels of $\alpha_{2}$-macroglobulin and may present a sharp front to the $\alpha_{2}$-band. In nephrotic syndrome the $\alpha_{2}$-zone may be increased relative to other protein bands because of their inability to pass through glomeruli (due to their size). In liver cirrhosis, 
Table 2. Changes in serum protein electrophoresis and associated conditions or disorders

\begin{tabular}{|c|c|c|}
\hline & Increase & Decrease \\
\hline Albumin & Dehydration & $\begin{array}{l}\text { Chronic cachectic or wasting disease } \\
\text { Chronic infections } \\
\text { Hemorrhage, burns } \\
\text { Protein-losing enteropathies } \\
\text { Impaired liver function } \\
\text { Malnutrition } \\
\text { Nephritic syndrome } \\
\text { Pregnancy }\end{array}$ \\
\hline$\alpha_{1}$-Globulins & Pregnancy & $\alpha_{1}$-Antitrypsin deficiency \\
\hline$\alpha_{2}$-Globulins & $\begin{array}{l}\text { Adrenal insufficiency } \\
\text { Adrenocorticosteroid therapy } \\
\text { Advanced diabetes mellitus } \\
\text { Nephritic syndrome }\end{array}$ & $\begin{array}{l}\text { Malnutrition } \\
\text { Megaloblastic anemia } \\
\text { Protein-losing enteropathy } \\
\text { Severe liver disease } \\
\text { Wilson's disease }\end{array}$ \\
\hline$\beta$-Globulins & $\begin{array}{l}\text { Biliary cirrhosis } \\
\text { Carcinoma (sometimes) } \\
\text { Cushing's disease } \\
\text { Diabetes mellitus (sometimes) } \\
\text { Hypothyroidism } \\
\text { Iron deficiency anemia } \\
\text { Malignant hypertension } \\
\text { Nephrosis } \\
\text { Polyarteritis nodosa } \\
\text { Obstructive jaundice } \\
\text { Third-trimester pregnancy }\end{array}$ & Protein malnutrition \\
\hline$\gamma$-Globulins & $\begin{array}{l}\text { Amyloidosis } \\
\text { Chronic infections } \\
\text { (granulomatous disease) } \\
\text { Chronic lymphocytic leukemia } \\
\text { Cirrhosis } \\
\text { Hodgkin's disease } \\
\text { Malignant lymphoma } \\
\text { Multiple myeloma } \\
\text { Rheumatoid and collagen disease }\end{array}$ & $\begin{array}{l}\text { Agammaglobulinemia } \\
\text { Hypogammaglobulinemia }\end{array}$ \\
\hline
\end{tabular}

diabetes mellitus, and malignant tumors (acute-phase reaction), the $\alpha_{2}$-band may be raised.

\section{$\alpha_{2}$-Interzone}

High levels of pre- $\beta$-lipoprotein are found in Frederickson type II hypercholesterolemia and in nephrotic syndrome for the same reasons mentioned above and may form an irregular band in this zone.

\section{$\beta$-Fraction}

The $\beta$-fraction may be separated into a $\beta_{1}$-band and a $\beta_{2}$-band but on graphical data is often represented as a single band. Transferrin comprises the $\beta_{1}$-band. An in- crease of $\beta_{1}$-proteins is typical for iron-deficiency anemia due to elevated levels of free transferrin, pregnancy and estrogen therapy. The $\beta_{2}$-band is formed by complement protein 3 (C3) and $\beta$-lipoprotein. IgA (immunoglobulin A), IgM, and sometimes IgG also can be identified in the $\beta$-fraction.

\section{$\gamma$-Fraction}

In the interpretation of SPE, great attention focuses on the $\gamma$-region, which is predominantly composed of immunoglobulins of the IgG type. The various immunoglobulin classes (IgG, IgA, IgM, IgD and IgE) are usually of $\gamma$-mobility and make up most of the $\gamma$-band, but they 
can also be found in the $\beta-\gamma$ - and $\beta$-regions, and may occasionally even extend into the $\alpha_{2}$-globulin area. The $\gamma$-globulin zone is decreased in agammaglobulinemia and hypogammaglobulinemia syndromes (e.g. IgA deficiency, newborns). IgA deficiency occurs in 1 out of 500 patients and often remains undetected. On SPE, IgA has the most anodal mobility (closer to the left side of the graphical output) and may lead to pallor in the $\gamma$-zone. Diseases that lead to an increase of $\gamma$-globulins include malignant lymphoma (multiple myeloma, Waldenström's macroglobulinemia, Hodgkin's disease, chronic lymphocytic leukemia), chronic infections, liver cirrhosis, amyloidosis, and rheumatological, granulomatous and connective tissue disorders (e.g. rheumatoid arthritis, systemic lupus erythematosus). Although many conditions can cause an increase in the $\gamma$-region, those that cause a homogenous spike-like peak in the focal region of the $\gamma$ globulin zone are of special interest (fig. 1b). These socalled monoclonal gammopathies constitute a group of disorders that are characterized by proliferation of a single, usually malignant clone of plasma cells that produce either a single class of intact immunoglobulins, heavy chains or light chains (Bence Jones protein) or a combination of these components. These proteins are known as paraproteins or M (monoclonal) proteins. Multiple myeloma is the most common cause of IgA and IgG paraproteinemias, but chronic lymphatic leukemia and lymphosarcoma may also produce M proteins (usually IgM). In Waldenström's macroglobulinemia, only IgM paraproteins can be found [2]. Be aware of gradients caused by high-volume infusion of plasma expanders that can falsely suggest malignant pathology.

\section{Indications in Internal Medicine}

SPE is always indicated when multiple myeloma, Waldenström's macroglobulinemia, amyloidosis or other protein disorders are suspected. The examination, however, should also be considered in 'red flag' situations such as: rouleaux formations on peripheral blood smear, elevated erythrocyte sedimentation rate, elevated serum viscosity, leukocy tosis, elevated total serum protein levels or hypercalcemia attributed to possible malignancy, Bence Jones proteinuria, new-onset anemia associated with renal insufficiency, unexplained peripheral neuropathy, pathologic fracture or lytic lesions on radiography, and recurrent infections from possible immunoglobulin deficiency $[4,5]$. If no M-gradient is detected on SPE but multiple myeloma or other disorders are still suspected, immunofixation should be performed. Immunofixation is more sensitive in identifying small monoclonal (M) proteins [2].

It is critical to differentiate monoclonal from polyclonal gammopathies. Monoclonal gammopathies are characterized by a homogenous formation of paraproteins that leads to a sharp, well-defined single peak (fig. 1b), whereas polyclonal gammopathies lead to a broad diffuse increased $\gamma$-band that may be caused by any reactive or inflammatory process and are associated with nonmalignant conditions. The differential diagnosis of mono- and polyclonal gammopathies is listed in table $3[6,7]$. Once a monoclonal gammopathy is identified by SPE, multiple myeloma must be differentiated from other causes according to table 3 [7].

\section{Interpretations of Results}

(a) Acute inflammation early phase ('acute-reaction protein pattern'): This pattern shows increased acutephase proteins and a normal to a decrease in albumin and transferrin levels (fig. 1c). This pattern is seen in early phases of infection, trauma, necrosis, infarction, burns, and chemical injury.

Albumin $=-\downarrow, \alpha_{1} \uparrow, \alpha_{2} \uparrow, \beta=, \gamma=$

(b) Acute inflammation late phase: Disorders with this pattern include acute infections in the late phase (e.g. pneumonia, bacterial meningitis, pyelonephritis, sepsis) when immunoglobulins from specific immune response are present (fig. 1d).

Albumin $\downarrow, \alpha_{1} \uparrow, \alpha_{2} \uparrow, \beta=, \gamma \uparrow$

(c) Chronic inflammation: Inflammatory disorders like chronic infections (e.g. viral hepatitis, tuberculosis, bronchiectasis, lues, osteomyelitis), chronic inflammatory bowel disease, rheumatoid arthritis, and connective tissue disease may show this pattern of dysproteinemia (fig. 1e).

Albumin $\downarrow, \alpha_{1}=, \alpha_{2}=, \beta=, \gamma \uparrow$

(d) Chronic active inflammation: This pattern may be present in chronic disorders with concomitant acute or 
Table 3. Differential diagnosis of mono- and polyclonal gammopathies

Monoclonal gammopathies

- Multiple myeloma

- Monoclonal gammopathy of undetermined significance

- Smoldering multiple myeloma

- Plasma cell leukemia

- Solitary plasmacytoma

- Waldenström's macroglobulinemia

- Heavy chain disease

- POEMS syndrome

- AL (light chain) amyloidosis

Polyclonal gammopathies

- Infections: viral: hepatitis, HIV, EBV, VZV; bacterial: endocarditis, osteomyelitis, bacteremia, tuberculosis

- Connective tissue diseases: connective tissue disease, temporal arteritis, rheumatoid arthritis, sarcoid

- Liver disease: cirrhosis, ethanol abuse, autoimmune hepatitis, viral-induced hepatitis, PBC, PSC

- Malignancies: solid tumors, ovarian tumors, lung cancer, HCC, renal tumors, gastric tumors

- Hematologic and lymphoproliferative disorders: lymphoma, leukemia, thalassemia, sickle cell anemia

- Other inflammatory conditions: gastrointestinal (CD, UC), pulmonary (bronchiectasis, cystic fibrosis, chronic bronchitis, pneumonitis, endocrine (Graves' disease, Hashimoto thyroiditis)

active inflammatory response like in exacerbated rheumatoid arthritis, systemic lupus erythematosus, chronic active hepatitis and for example chronic endocarditis (fig. 1f).

Albumin $\downarrow, \alpha_{1} \uparrow, \alpha_{2} \uparrow, \beta=, \gamma \uparrow$

(e) Malignant tumors: Most of the malignant tumors show an increase of $\alpha_{1}$-globulins and especially $\alpha_{2}$-globulins due to an increase of acute-phase proteins (fig. $1 \mathrm{~g}$ ). An increase of the $\gamma$-fraction can occasionally be observed in end-stage patients. Tumors with immunosuppressive properties (e.g. lymphomas) may also decrease the $\gamma$-fraction.

Albumin $\downarrow, \alpha_{1} \uparrow, \alpha_{2} \uparrow, \beta=, \gamma=$ or $\downarrow$ or $\uparrow$

(f) Liver failure: Different forms of liver cirrhosis, chronic active hepatitis, necrotizing forms of acute hepatitis, and toxic liver damage (alcohol) may lead to this dysproteinemia (fig. 1h). In autoimmune hepatitis a marked increase in the $\gamma$-fraction is typical.

Albumin $\downarrow, \alpha_{1}=$ or $\downarrow, \alpha_{2}=$ or $\downarrow, \beta=, \gamma=\uparrow \uparrow$

(g) Nephrotic syndrome: Kidney diseases with glomerular damage and urinary protein loss of $>3 \mathrm{~g} /$ day can lead to this pattern. The increase of the $\alpha_{2}$-zone can be very pronounced and sometimes difficult to differentiate from monoclonal gammopathies with an M-gradient (fig. 1i).

Albumin $\downarrow, \alpha_{1} \downarrow, \alpha_{2} \uparrow \uparrow, \beta \uparrow, \gamma \downarrow$

(h) Antibody deficiency: Antibody deficiencies can either involve a single fraction or all fractions of immunoglobulins. Patients with congenital antibody deficiency usually present with recurrent infections since early childhood. To obtain a comprehensive medical history is therefore paramount. Acquired antibody deficiencies can be induced by medical therapy (chemotherapeutics, prednisone), by malignant tumors (chronic lymphatic leukemia, Bence Jones myeloma, solid tumors), or nephrotic syndrome (fig. 1j).

Albumin $=, \alpha_{1}=, \alpha_{2}=, \beta=, \gamma \downarrow$

(i) Pregnancy: In the first trimester, the $\alpha_{2}$-globulins increase (fig. $1 \mathrm{k}$ ) and in the second and third trimesters, the $\beta$-fraction may also be increased due to elevated serum transferrin levels in the setting of iron-deficiency anemia (fig. 11).

Albumin $\downarrow, \alpha_{1}=, \alpha_{2} \uparrow, \beta \uparrow, \gamma=$

\section{Case Presentations in Gastroenterology}

\section{Chronic Liver Disease}

SPE is a useful tool in the work-up of patients with chronic liver disease, especially in liver cirrhosis and chronic active hepatitis. It may be an argument for the presence of liver cirrhosis, if biopsy is not intended. In these patients, a decrease of albumin and $\alpha_{2}$-globulin can uniformly be seen. The $\gamma$-fraction is often polyclonal (i.e. dome-shaped, see fig. $1 \mathrm{~g}, \mathrm{~h}$ ) and the normal depression 
between the $\beta$ - and $\gamma$-band may be missing when liver cirrhosis is present ( $\beta-\gamma$ bridging).

\section{Hepatocellular Carcinoma}

Most of the hepatocellular carcinomas arise in a cirrhotic liver, so the findings above apply as well. When high serum levels of AFP are present, electrophoresis can show a sharp band between the albumin and the $\alpha_{1}$-zone.

\section{Amyloidosis}

The presence of a localized band on SPE (fig. 1b) in adults with nephrotic syndrome, congestive heart failure, peripheral neuropathy, and malabsorption suggests the possibility of amyloidosis. In the intestinal tract, amyloid deposition can be found in the walls of blood vessels leading to ischemia and possible infarction, in the muscle layers of the intestinal wall, causing dysmotility, and in the muscularis mucosa, resulting in impaired absorption [8]. Clinical signs and symptoms due to amyloidosis can be occur throughout the whole gastrointestinal tract: macroglossia [9], diarrhea or constipation, megacolon, fecal incontinence [10], gastrointestinal bleeding (presumably from increased capillary fragility) [11], intestinal infarction [12], protein-losing enteropathy [13], or rectal prolapse. A third of all patients present with hepatosplenomegaly or ascites [10].

\section{Multiple Myeloma}

Symptoms from multiple myeloma may involve the gastrointestinal tract in the presence of light-chain amyloidosis or due to local infiltration by plasmocytomas (fig. 1b). $21 \%$ of patients with amyloidosis have multiple myeloma [10] and most of them present with neoplastic bowel wall infiltration and dysmotility. This tumor may be asymptomatic or may cause anorexia, vomiting, abdominal pain, or bleeding.

\section{Waldenström's Macroglobulinemia}

Gastrointestinal infiltration is also found in patients with Waldenström's macroglobulinemia. Extracellular IgM paraproteins are deposited in the lamina propria of the intestinal wall and in mesenteric nodes. Symptoms may include diarrhea, abdominal pain, flatulence, gastrointestinal hemorrhage, and weight loss [14] (fig. 1b).

\section{Iron-Deficiency Anemia}

Patients with iron-deficiency anemia may produce a localized band in the $\beta$-zone due to high concentrations of transferrin (fig. 1l), sometimes falsely interpreted as the presence of an M-protein.

\section{$\alpha_{1}$-Antitrypsin Deficiency}

A marked reduction of the $\alpha_{1}$-zone is typically due to a deficiency of $\alpha_{1}$-antitrypsin (fig. $1 \mathrm{~m}$ ). In the work-up of patients with unexplained cirrhosis, SPE is therefore mandatory.

\section{POEMS Syndrome}

A rare cause of ascites includes the POEMS syndrome (polyneuropathy, organomegaly, endocrinopathy, $\underline{\mathrm{M}}$ component, and skin changes) (fig. 1b).

\section{Inflammatory Bowel Disease}

In inflammatory bowel disease you can find several changes in electrophoresis, alone or in combination. Impaired absorption from intestinal inflammation may lead to malassimilation and malnutrition showing a decrease of albumin, and the $\alpha_{1^{-}}$and $\beta$-zone on SPE. For the same reasons, iron-deficiency anemia may also be present presenting a localized band in the $\beta$-zone (see above, fig. 11). Depending on the activity state of the inflammatory bowel disease, the patterns of inflammation found with electrophoresis can vary from acute inflammatory response (fig. 1c) in a flare of the disease, to a chronic inflammatory response (fig. 1e) during stable phases or even a normal pattern when the patient is in remission.

\section{Conclusion}

SPE is inexpensive and widely available in hospitals and clinics by virtue of its common use to monitor patients with multiple myeloma. In multiple myeloma, SPE monitors for paraproteins and is the accepted method for monitoring the clinical course of multiple myeloma. In the screening of diseases other than multiple myeloma and especially in patients with gastrointestinal disorders, SPE is not often used. Hopefully, with understanding and knowledge how to interpret results, this will change in the future.

\section{Acknowledgments}

This work is supported by Grant 320000-114009/1 (to S.R.V.), and 3347C0-108792/1 (Swiss Inflammatory Bowel Disease Cohort Study) from the Swiss National Science Foundation. 


\section{References}

-1 O'Connell TX, Horita TJ, Kasravi B: Understanding and interpreting serum protein electrophoresis. Am Fam Physician 2005; 71:105-112.

$\checkmark 2$ Kyle RA: The monoclonal gammopathies. Clin Chem 1994;40:2154-2161.

>3 Kyle RA: Sequence of testing for monoclonal gammopathies. Arch Pathol Lab Med 1999;123:114-118.

4 Ravel R: Clinical Laboratory Medicine: Clinical Application of Laboratory Data, ed 6. St Louis, Mosby, 1995.

5 Criteria for the classification of monoclonal gammopathies, multiple myeloma and related disorders: a report of the International Myeloma Working Group. Br J Haematol 2003;121:749-757.
6 Dispenzieri A, Gertz MA, Therneau TM, Kyle RA: Retrospective cohort study of 148 patients with polyclonal gammopathy. Mayo Clin Proc 2001;76:476-487.

$\checkmark 7$ George ED, Sadovsky R: Multiple myeloma: recognition and management. Am Fam Physician 1999;59:1885-1894.

8 Yamada M, Hatakeyama S, Tsukagoshi H: Gastrointestinal amyloid deposition in AL (primary or myeloma-associated) and AA (secondary) amyloidosis: diagnostic value of gastric biopsy. Hum Pathol 1985;16:12061211.

$\checkmark 9$ Schwartz Y, Tamse A, Kissin E, Shani M: An unusual case of temporomandibular joint arthropathy in systemic primary amyloidosis. J Oral Med 1979;34:40-44.

$>10$ Kyle RA, Greipp PR: Amyloidosis. Clinical and laboratory features in 229 cases. Mayo Clin Proc 1983;58:665-683.
11 Levy DJ, Franklin GO, Rosenthal WS: Gastrointestinal bleeding and amyloidosis. Am J Gastroenterol 1982;77:422-426.

12 Choi HS, Heller D, Picken MM, Sidhu GS, Kahn T: Infarction of intestine with massive amyloid deposition in two patients on longterm hemodialysis. Gastroenterology 1989; 96:230-234.

13 Hunter AM, Borsey DQ, Campbell IW, Macaulay RA: Protein-losing enteropathy due to gastrointestinal amyloidosis. Postgrad Med J 1979;55:822-823.

14 Bohus R, Waltzer WC, Frischer Z, Gonder $\mathrm{M}$ : Retroperitoneal haemorrhage with abscess formation complicating Waldenström's macroglobulinaemia. Int Urol Nephrol 1985;17:255-259. 